\title{
Stress Analysis of Asphalt Concrete Deck Pavement on Steel Bridge based on Burgers Model and interlayer contact
}

\author{
Xuntao Wang ${ }^{1, a}$, Jianhu Feng ${ }^{2, b}$, Hu Wang ${ }^{3, c}$ \\ ${ }^{1,2,3}$ School of Science, Chang'an University, Xi'an Shaanxi, 710064, China \\ aEmail:wxt5288@126.com, ${ }^{\text {b} E m a i l: j h f e n g @ c h d . e d u . c n, ~}{ }^{\mathrm{C} E m a i l: w h 89 @ c h d . e d u . c n ~}$
}

\begin{abstract}
Keywords: deck pavement, asphalt concrete, viscoelasticity, interlayer contact, maximum stress, disengaging area.

Abstract: A three-dimensional finite element steel bridge and its deck pavement were established by ANSYS software to simulate the influence of different model and bonding failure between adjacent layers on stress values of asphalt concrete deck pavement. The stress values of asphalt concrete deck pavement were calculated and analyzed with consideration of the characteristic of asphalt concrete and interlayer bonding condition. The influence of the disengaging area between the upper layer and lower layer of asphalt concrete on the stress values of asphalt concrete deck pavement was computed and analyzed. At the same time, the influence of the disengaging area between the lower layer of asphalt concrete and the waterproof layer on the stress values of asphalt concrete deck pavement was calculated and analyzed.
\end{abstract}

\section{Introduction}

The steel bridge is widely used in the construction of long-span bridge ${ }^{[1]}$. Steel bridge deck pavement is an important structural layer of a steel bridge, which can protect the underlying steel deck from damages such as corrosion. Asphalt concrete deck pavement is the most common type of pavement for steel bridge deck pavement. However, investigations ${ }^{[2]}$ had shown that cracking might occur as a major distress in asphalt concrete deck pavement on steel bridge. If no timely treatments are provided, further deteriorations such as potholes and bonding failures would occur.

Asphalt concrete paved on steel bridge was usually considered to be elastic material by many researchers $^{[3,4]}$, and adjacent layers of deck pavement were also considered to be completely continuous with each other ${ }^{[3-5]}$. This situation denotes as ECCS model.

In fact, asphalt concrete is viscoelastic material ${ }^{[6,7]}$, and temperature has a significant influence on characteristic of asphalt concrete. At the same time, bonding condition between adjacent layers is not completely continuous ${ }^{[8,9]}$, which was neglected by many researchers.

In this paper asphalt concrete deck pavement on steel bridge serve as viscoelastic material, and asphalt concrete material follows Burgers model. In addition, interlayer bonding condition carry through interlayer contact, which follow the Coulomb friction model, and interlayer contact will be realized by contact element and target element in ANSYS software. This situation denotes as VCCT model.

To reasonably predict and prevent distress of asphalt concrete deck pavement on steel bridge, stress values of asphalt concrete deck pavement calculated by the ECCS model and the VCCT model will be compared and analyzed. Stress values of asphalt concrete deck pavement on steel bridge will be calculated and analyzed on the basis of Burgers model and interlayer contact when bonding failures occur between adjacent layers. 


\section{Burgers model and Coulomb friction model}

\section{Burges model and parameters of Prony series}

Burgers model is considered to be suitable to describe the viscoelasticity of asphalt concrete, and the creep function of Burgers model under a constant stress $\sigma_{0}$ can be described by ${ }^{[10,11]}$ :

$$
\varepsilon(t)=\sigma_{0}\left[\frac{1}{E_{1}}+\frac{t}{\eta_{1}}+\frac{1}{E_{2}}\left(1-e^{E_{2} t \eta_{2}}\right)\right]
$$

where $t$ is time, $\varepsilon$ can be obtained by laboratory test, $E_{1}$ and $E_{2}$ are the elastic modulus of elastic component, $\eta_{1}$ and $\eta_{2}$ are the coefficient of viscosity of viscous component. The parameter $E_{1}, E_{2}, \eta_{1}$ and $\eta_{2}$ can be estimated from a fitted curves of equation (1). Table $1^{[12]}$ lists the estimated value of the parameter $E_{1}, E_{2}, \eta_{1}$ and $\eta_{2}$ at $50^{\circ} \mathrm{C}$. The parameter $E_{1}, E_{2}, \eta_{1}$ and $\eta_{2}$ can be transferred into the shear modulus parameter $\alpha_{1}, \alpha_{2}, \tau_{1}$ and $\tau_{2}$ of Prony series by a certain rules ${ }^{[10,11]}$, and the shear modulus parameters listed in the Table. 2.

Table 1. The estimated value of the viscoelastic parameters of asphalt concrete

\begin{tabular}{ccccc}
\hline Asphalt concrete & $E_{1}(\mathrm{MPa})$ & $E_{2}(\mathrm{MPa})$ & $\eta_{1}(\mathrm{MPa} / \mathrm{s})$ & $\eta_{2}(\mathrm{MPa} / \mathrm{s})$ \\
\hline AC-13C & 313.6 & 61.2 & 167806.5 & 10668.8 \\
\hline AC-20C & 274.4 & 45.2 & 177037.1 & 9747.3 \\
\hline
\end{tabular}

Table 2. The shear modulus parameters of asphalt concrete

\begin{tabular}{ccccc}
\hline Asphalt concrete & $\alpha_{1}$ & $\alpha_{2}$ & $\tau_{1}(\mathrm{~s})$ & $\tau_{2}(\mathrm{~s})$ \\
\hline AC-13C & 0.8725 & 0.1275 & 23.3 & 3338.9 \\
\hline AC-20C & 0.8890 & 0.1110 & 24.9 & 4645.1 \\
\hline
\end{tabular}

\section{Coulomb friction model}

When a certain layer and its adjacent layer(s) are assumed to be interlayer contact with each other, the shear stress transmission between the adjacent layers follows Coulomb friction model ${ }^{[13]}$ :

$$
\begin{gathered}
\tau_{\lim }=\mu P+b \\
|\tau| \leq \tau_{\lim }
\end{gathered}
$$

Where $\tau_{\lim }$ is ultimate shear stress, $\mu$ is the sliding friction coefficient, it equals 0.5 in this paper, $P$ is the contact compressive stress in normal direction, $b$ is the cohesion between the adjacent layer, $\tau$ is the equivalent shearing stress. In equation (2), if $\mu$ equals 0 or $P$ equals 0 , the cohesion $b$ still exist, if $b$ equals 0 , two adjacent layers take place cohesive failure. In inequation (3), 
when $|\tau|$ between two adjacent layers is less than or equal $\tau_{\lim }$, the two layers keep sticking, or the two layers start to slide.

\section{Computation Model}

In this study, a steel bridge was simulated by ANSYS software, and the upper layer of asphalt concrete (or ULAC for short), the lower layer of asphalt concrete (or LLAC for short) and the waterproof layer (or WPL for short) overlaid on the steel bridge. The material parameters are listed in table 3. The ECCS model used elastic parameters, and the VCCT model used viscoelastic parameters. The ULAC and the LLAC were assumed to be in contact with each other. The LLAC and the WPL were assumed to be in contact with each other. The WPL and the steel deck plate were assumed to be in contact with each other. The cross section size of the steel bridge (with a span of $30 \mathrm{~m}$ ) and its pavement are shown in Fig. 1, and the direction of z-axis was the same with the driving direction. The loading position (or LP for short) is showed in the figure 1 at the mid-span, and the pavement structure subjected to single-axis double-wheel load ${ }^{[14]}$ of $140 \mathrm{KN}$. Other structure parameters of steel bridge are listed in table 4 . When the emergency braking occurred, the braking force $F$ will act on the ULAC. The braking force $F=\lambda G$, where $\lambda$ is the braking coefficient,

Table 3. Material Parameters

\begin{tabular}{ccccc}
\hline Structural layer & Thickness $(\mathrm{m})$ & Elastic modulus(MPa) & Poisson's ratio \\
\hline The ULAC & 0.04 & $1400 /$ viscoelastic parameter & 0.25 \\
\hline The LLAC & 0.06 & $1200 /$ viscoelastic parameter & 0.25 \\
\hline The WPL & 0.002 & 150 & 0.30 \\
\hline The steel bridge & - & 210000 & 0.30 \\
\hline
\end{tabular}

Figure 1. Cross Section of Model and Loading Position (Unit: m)

Table 4 Structure Parameters of Steel Bridge

\begin{tabular}{lclc}
\hline Item & Value $(\mathrm{m})$ & Item & Value $(\mathrm{m})$ \\
\hline Top deck thickness & 0.030 & U-rib thickness & 0.016 \\
\hline Bottom deck thickness & 0.030 & Diaphragm space & 3.000 \\
\hline Web thickness & 0.025 & Diaphragm thickness & 0.016 \\
\hline
\end{tabular}


it equals 0.5 , and $G$ is the wheel load. The maximum transverse tensile stress $\sigma_{x \max }$, the maximum longitudinal tensile stress $\sigma_{z \max }$, the maximum transverse shear stress $\tau_{x y \max }$ and the maximum longitudinal shear stress $\tau_{y z \max }$ of asphalt concrete deck pavement would be calculated for analyzing stress of asphalt concrete deck pavement.

\section{Stress calculation and analysis for asphalt concrete deck pavement}

\section{Influence of model and loading position on stress of asphalt concrete pavement}

Stress values of asphalt concrete deck pavement were calculated by ECCS model and VCCT model respectively, and the results are listed in table 4 and table 5 respectively.

Table 5 Stress Values of Asphalt Concrete Deck Pavement (Unit: MPa)

\begin{tabular}{|c|c|c|c|c|c|}
\hline $\begin{array}{l}\text { Asphalt } \\
\text { Concrete }\end{array}$ & $\begin{array}{l}\text { Loading } \\
\text { Position }\end{array}$ & $\sigma_{x \max }$ & $\sigma_{z \max }$ & $\tau_{x y \max }$ & $\tau_{y z \max }$ \\
\hline \multirow{4}{*}{ The LLAC } & LP1 & 0.017540 & 0.054663 & 0.220139 & 0.331670 \\
\hline & LP2 & 0.017898 & 0.054004 & 0.189278 & 0.326387 \\
\hline & LP3 & 0.073113 & 0.052495 & 0.206617 & 0.324825 \\
\hline & LP4 & 0.167223 & 0.051559 & 0.193421 & 0.318134 \\
\hline \multirow{4}{*}{ The ULAC } & LP1 & 0.085119 & 0.264351 & 0.167185 & 0.339005 \\
\hline & LP2 & 0.106446 & 0.254907 & 0.136609 & 0.327410 \\
\hline & LP3 & 0.231211 & 0.254542 & 0.147444 & 0.327325 \\
\hline & LP4 & 0.368666 & 0.252356 & 0.123553 & 0.326026 \\
\hline \multicolumn{6}{|c|}{ Table 6 Stress Values of Asphalt Concrete Deck Pavement (Unit: MPa) } \\
\hline $\begin{array}{l}\text { Asphalt } \\
\text { Concrete }\end{array}$ & $\begin{array}{l}\text { Loading } \\
\text { Position }\end{array}$ & $\sigma_{x \max }$ & $\sigma_{z \max }$ & $\tau_{x y \max }$ & $\tau_{y z \max }$ \\
\hline \multirow{4}{*}{ The LLAC } & LP1 & 0.160062 & 0.589923 & 0.255652 & 0.293556 \\
\hline & LP2 & 0.154796 & 0.576301 & 0.226232 & 0.283759 \\
\hline & LP3 & 0.175858 & 0.583152 & 0.236399 & 0.284076 \\
\hline & LP4 & 0.187193 & 0.575585 & 0.212973 & 0.282472 \\
\hline \multirow{4}{*}{ The ULAC } & LP1 & 0.300322 & 0.616159 & 0.225298 & 0.352905 \\
\hline & LP2 & 0.357780 & 0.599682 & 0.192028 & 0.340645 \\
\hline & LP3 & 0.380878 & 0.601544 & 0.200762 & 0.339909 \\
\hline & LP4 & 0.441316 & 0.598894 & 0.169440 & 0.339538 \\
\hline
\end{tabular}

Compared with table 4 and table 5, stress values of asphalt concrete deck pavement calculated by ECCS model are smaller than stress values of asphalt concrete deck pavement calculated by VCCT model at the corresponding loading position. The results of ECCS model underestimate the stress values of asphalt concrete deck pavement. The maximum transverse tensile stress $\sigma_{x \max }$ of the LLAC and ULAC increased from LP1 to LP4 in table 4 and table 5. The maximum tensile 
stress $\sigma_{x \max }$ and $\sigma_{z \max }$ of ULAC are greater than the maximum tensile stress $\sigma_{x \max }$ and $\sigma_{z \max }$ of ULAC at correspondingly loading position. The maximum transverse shear stress $\tau_{x y \max }$ of LLAC is greater than the maximum transverse shear stress $\tau_{x y \max }$ of ULAC at correspondingly loading position, but the maximum longitudinal shear stress $\tau_{y z \max }$ of ULAC is greater than the maximum transverse shear stress $\tau_{y z \max }$ of LLAC at correspondingly loading position. The maximum transverse tensile stress $\sigma_{x \max }$ of the LLAC and ULAC occurred at LP4, but the maximum longitudinal tensile stress $\sigma_{z \max }$ of the LLAC and ULAC occurred at LP1. The maximum shear $\operatorname{stress} \tau_{x y \max }$ and $\tau_{y z \max }$ also occurred at LP1.

\section{Stress of asphalt concrete pavement when disengaging area existing}

As the vehicle load acted chronically and repeatedly on the asphalt concrete pavement, the disengaging area (bonding failure) might occur between the adjacent layers. When the disengaging area existed between the adjacent layers, the cohesion $b$ there was assumed to be 0 . Six types of disengaging area were shown in Fig. 2, which existed under the left double wheel at loading position 1, and the shaded area was the disengaging area.
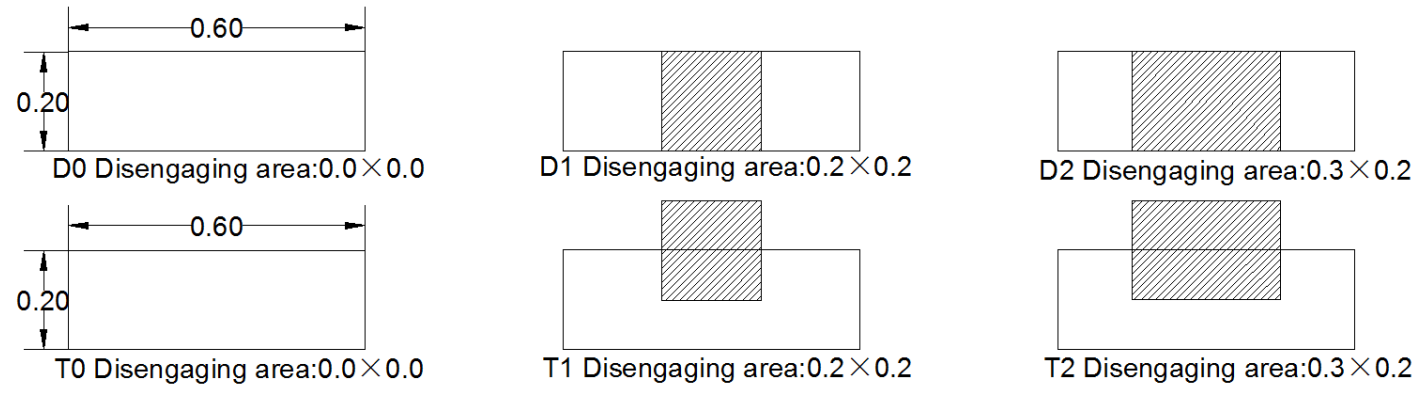

Figure 2 Type of Disengaging area under Loading Position 1 (Unit:m²)

Firstly, assumed that the six types of disengaging area appeared respectively between the ULAC and the LLAC, and the stress values of asphalt concrete deck pavement were calculated by VCCT model. The results were listed in table 6 . The maximum tensile stress values of the LLAC and ULAC increased with "D" type and "T" type of disengaging area increasing, and the maximum shear stress values of the LLAC and ULAC also increased with "D" type and "T" type of disengaging area increasing. When disengaging area is greater than 0 , the maximum tensile stress and maximum shear stress of the ULAC are greater than the maximum tensile stress and maximum shear stress of the LLAC at the corresponding types of disengaging area. The max tensile stress $\sigma_{x \max }$ and $\sigma_{z \max }$ of the ULAC have a substantial increase at the "D" type of disengaging area, which all are greater than 1.1MPa.

Now assumed that the six types of disengaging area appeared respectively between the LLAC and the WPL, and the stress values of asphalt concrete deck pavement were also calculated by VCCT model. The results were listed in table 7. The maximum tensile stress values of the LLAC 
and ULAC increased with " $\mathrm{D}$ " type and "T" type of disengaging area increasing, and the maximum longitudinal shear stress $\tau_{y z \max }$ of the LLAC and ULAC increased with " $\mathrm{D}$ " type and " $\mathrm{T}$ " type of

Table 7 stress value of the asphalt concrete deck pavement

\begin{tabular}{|c|c|c|c|c|c|}
\hline $\begin{array}{l}\text { Asphalt } \\
\text { Concrete }\end{array}$ & $\begin{array}{c}\text { Disengaging } \\
\text { Area }\left(\mathrm{m}^{2}\right)\end{array}$ & $\sigma_{x \max }(\mathrm{MPa})$ & $\sigma_{z \max }(\mathrm{MPa})$ & $\tau_{x y \max }(\mathrm{MPa})$ & $\tau_{y z \max }(\mathrm{MPa})$ \\
\hline \multirow{6}{*}{ The LLAC } & D0:0.0×0.0 & 0.160062 & 0.589923 & 0.255652 & 0.293556 \\
\hline & D1:0.2 $2 \times 0.2$ & 0.549799 & 0.672864 & 0.255642 & 0.457713 \\
\hline & $\mathrm{D} 2: 0.3 \times 0.2$ & 0.649070 & 0.841731 & 0.255646 & 0.463046 \\
\hline & $\mathrm{T} 0: 0.0 \times 0.0$ & 0.160062 & 0.589923 & 0.255652 & 0.293556 \\
\hline & $\mathrm{T} 1: 0.2 \times 0.2$ & 0.406818 & 0.822901 & 0.255641 & 0.293542 \\
\hline & $\mathrm{T} 2: 0.3 \times 0.2$ & 0.431975 & 0.930613 & 0.255634 & 0.295897 \\
\hline \multirow{6}{*}{ The ULAC } & D0: $0.0 \times 0.0$ & 0.300322 & 0.616159 & 0.225298 & 0.352905 \\
\hline & D1:0.2 $2 \times 0.2$ & 0.602446 & 1.144340 & 0.261169 & 0.506295 \\
\hline & $\mathrm{D} 2: 0.3 \times 0.2$ & 1.182120 & 1.473640 & 0.280804 & 0.720824 \\
\hline & T0:0.0×0.0 & 0.300322 & 0.616159 & 0.225298 & 0.352905 \\
\hline & $\mathrm{T} 1: 0.2 \times 0.2$ & 0.413036 & 0.831426 & 0.225284 & 0.505613 \\
\hline & $\mathrm{T} 2: 0.3 \times 0.2$ & 0.578139 & 0.998716 & 0.225276 & 0.543884 \\
\hline
\end{tabular}

Table 8 stress value of the asphalt concrete deck pavement

\begin{tabular}{|c|c|c|c|c|c|}
\hline $\begin{array}{l}\text { Asphalt } \\
\text { Concrete }\end{array}$ & $\begin{array}{c}\text { Disengaging } \\
\operatorname{Area}\left(\mathrm{m}^{2}\right)\end{array}$ & $\sigma_{x \max }(\mathrm{MPa})$ & $\sigma_{z \max }(\mathrm{MPa})$ & $\tau_{x y \max }(\mathrm{MPa})$ & $\tau_{y z \max }(\mathrm{MPa})$ \\
\hline \multirow{6}{*}{ The LLAC } & D0:0.0 $0 \times 0.0$ & 0.160062 & 0.589923 & 0.255652 & 0.293556 \\
\hline & D1:0.2 $2 \times 0.2$ & 0.565728 & 0.999195 & 0.255639 & 0.379068 \\
\hline & D2:0.3×0.2 & 0.685711 & 1.189490 & 0.255632 & 0.411522 \\
\hline & T0:0.0 $0 \times 0.0$ & 0.160062 & 0.589923 & 0.255652 & 0.293556 \\
\hline & $\mathrm{T} 1: 0.2 \times 0.2$ & 0.431359 & 0.711058 & 0.255644 & 0.339187 \\
\hline & $\mathrm{T} 2: 0.3 \times 0.2$ & 0.447602 & 0.830381 & 0.255640 & 0.356204 \\
\hline \multirow{6}{*}{ The ULAC } & D0:0.0 $0 \times 0.0$ & 0.300322 & 0.616159 & 0.225298 & 0.352905 \\
\hline & D1:0.2×0.2 & 0.448389 & 0.779737 & 0.225295 & 0.412732 \\
\hline & D2:0.3×0.2 & 0.502330 & 0.863793 & 0.225293 & 0.431543 \\
\hline & T0:0.0×0.0 & 0.300322 & 0.616159 & 0.225298 & 0.352905 \\
\hline & $\mathrm{T} 1: 0.2 \times 0.2$ & 0.389620 & 0.616181 & 0.225298 & 0.406917 \\
\hline & $\mathrm{T} 2: 0.3 \times 0.2$ & 0.424681 & 0.635482 & 0.225297 & 0.419045 \\
\hline
\end{tabular}

disengaging area increasing. The maximum transverse shear stress $\tau_{x y \max }$ of the ULAC and LLAC had a very small change. When disengaging area is greater than 0 , the maximum tensile stress $\sigma_{x \max }$ and $\sigma_{z \max }$ of the LLAC are greater than the maximum tensile stress $\sigma_{x \max }$ and $\sigma_{z \max }$ of the ULAC at the corresponding types of disengaging area. When disengaging area is greater than 0 , the maximum transverse shear stress $\tau_{x y \max }$ of the LLAC are greater than the maximum transverse shear stress $\tau_{x y \max }$ of the ULAC at the corresponding types of disengaging area, but the maximum longitudinal shear stress $\tau_{y z \max }$ of the LLAC are less than the maximum longitudinal shear 
$\operatorname{stress} \tau_{y z \max }$ of the ULAC at the corresponding types of disengaging area.

Stress values of the ULAC in table 6 are greater than stress values of the ULAC in table 7 at the corresponding types of disengaging area. It means that disengaging area between the ULAC and the LLAC had a significant influence on the stress values of the ULAC. When disengaging area is greater than 0 , the maximum longitudinal tensile stress $\sigma_{z \max }$ of the LLAC in table 7 are greater the maximum longitudinal tensile stress $\sigma_{z \max }$ of the LLAC in table 6 at the corresponding" D"types of disengaging area. It means that disengaging area between the LLAC and the WPL had a significant influence on the maximum longitudinal tensile stress $\sigma_{z \max }$ of the LLAC at the"D"types of disengaging area. When disengaging area is greater than 0 , the maximum longitudinal tensile stress $\sigma_{x \max }$ of the LLAC in table 7 are greater the maximum longitudinal tensile stress $\sigma_{x \max }$ of the LLAC in table 6 at the corresponding" $T$ "types of disengaging area. It means that disengaging area between the LLAC and the WPL had a significant influence on the maximum longitudinal tensile stress $\sigma_{x \max }$ of the LLAC at the "T"types of disengaging area. Compared with the stress values of the LLAC and ULAC at " $T$ " types of disengaging area, the stress values of the LLAC and ULAC at "D" types of disengaging area were no less than them. This means that the relative position of the disengaging area and the loading area have an influence on the stress values of the LLAC and ULAC.

\section{Conclusions}

(1) Compared with the results of the VCCT model, the results of the ECCS model underestimate the stress values of asphalt concrete deck pavement. This is a reason for explaining the premature failure of asphalt concrete deck pavement.

(2) When the bonding failure occurred between the adjacent layers, the bigger the disengaging area was, the greater the stress values of the ULAC and LLAC were. The "D" type of disengaging area has a significant influence on the maximum tensile stress of the ULAC.

(3) When the disengaging area occurred between the ULAC and the LLAC, the maximum tensile stress values of the ULAC changed obviously. When the disengaging area occurred between the LLAC and the WPL, the maximum tensile stress values of the LLAC changed obviously.

(4) The relative position of the disengaging area and the loading area had an influence on the stress values of the LLAC and ULAC.

\section{Acknowledgements}

This work was financially supported by the National Natural Science Foundation of China (No. 11601037) and the Special Fund for Basic Scientific Research of Central Colleges in Chang'an University (No. 310812171002). 


\section{References}

[1] T. W. Kim, J. Baek, H. J. Lee, et al. Effect of Pavement Design Parameters on the Behaviour of Orthotropic Steel Bridge Deck Pavements under Traffic Loading: International Journal of Pavement Engineering, 15.5(2014), p. 471-482.

[2] L. Chen, Z. Qian, J. Wang. Multiscale Numerical Modeling of Steel Bridge Deck Pavements Considering Vehicle-Pavement Interaction: International Journal of Geomechanics, 16.1(2016), p. B4015002_1-8.

[3] T. J. Chen, Z. D. Qian, W. Huang. Analysis of Dynamic Response of Deck Pavement for Large-span Steel Bridge: Journal of Highway \& Transportation Research \& Development, 3.2(2008), p. 82-85. (in Chinese)

[4] X. Q. Xu. Super Excellent Ant Colony Optimization Strategy for Long-span Steel Bridges Deck Pavement Design: Journal of Highway \& Transportation Research \& Development, 26.1(2009), p. 1-6.(in Chinese)

[5] E. Bocci, F. Canestrari. Analysis of Structural Compatibility at Interface Between Asphalt Concrete Pavements and Orthotropic Steel Deck Surfaces: Transportation Research Record Journal of the Transportation Research Board, 2293(2012), p. 1-7.

[6] E. Bocci, A. Graziani, F. Canestrari. Mechanical 3D Characterization of Epoxy Asphalt Concrete for Pavement layers of Orthotropic Steel Decks: Construction \& Building Materials, 79(2015), p. 145-152.

[7] A. W. Ahmed, S. Erlingsson. Numerical Validation Of Viscoelastic Responses of A Pavement Structure in A Full-scale Accelerated Pavement Test: International Journal of Pavement Engineering, 18.1(2017), p. 47-59.

[8] L. Zhen, I. L. Al-Qadi, S. H. Carpenter, et al. Interface Bonding Between Hot-mix Asphalt and Various Portland Cement Concrete Surfaces: Laboratory Assessment: Transportation Research Record, 11.2057 (2009), p. 46-53.

[9] H. Kim, M. Arraigada, C. Raab, et al. Numerical and Experimental Analysis for the Interlayer Behavior of Double-layered Asphalt Pavement Specimens: Journal of Materials in Civil Engineering, 23.1(2011), p. 12-20.

[10] J. Y. Chen, C. H. Zhou, Z. R. Wang. Data Processing and Viscoelastic Computation For Creep Test of Asphalt Mixture: Journal Of Southeast University(Natural Science Edition), 37.6(2007), p. 1091-1095.( in Chinese)

[11]F. S. Wang. A 3D FEM Analysis Of Creep Deformation Law Of Asphalt Pavement Based On Burgers Viscoelastic Model: Industrial Construction, 44.3(2014), p. 104 -109. ( in Chinese)

[12]Z. Y. He, T. Lei, H. X. Chen, et al. A 3D Visco-elasto-plastic Finite Element Analysis of the Asphalt Pavement Rutting Deformation: Journal of Chongqing Jianzhu University, 30.6(2008), p. 32-36. ( in Chinese)

[13]X. M. Wang, in: ANSYS Structural Analysis Unit and Application, edited by China Communications Press, Beijing, 2009. (in Chinese)

[14]CCCC Highway Planning and Design Institute, in: JTGD60-2004 General Code for Design of Highway Bridges and Culverts, edited by Ministry of Communications of the People's Republic of China, Beijing, 2004. (in Chinese) 